\title{
Integrated modeling of compact power lines
}

\author{
NV Buyakova ${ }^{1, *}, A V$ Kryukov $^{2}$, and Le Van $\mathrm{Thao}^{3}$ \\ ${ }^{1}$ Power Supply of the Industrial Enterprises Department at Angarsk State Technical University, 60 Tchaikovsky St., Angarsk, 665835 , \\ Russia \\ ${ }^{2}$ Transport Electric Engineering Department at Irkutsk state transport university, 15 Chernyshevsky St., Irkutsk, 664074, Russia \\ ${ }^{3}$ Power Supply and Electrical Equipment Department at Irkutsk national research technical university, 83 Lermontov St., Irkutsk, \\ 664074, Russia
}

\begin{abstract}
The aim of the research presented in the article is to develop methods and means for integrated modeling of compact expanded capacity power lines. Algorithms for determining modes of electrical energy systems were used based on phase coordinates based on application of elements models in form of lacelike equivalent networks with fully-meshed topology. These models and methods were implemented in Fazonord-APC software application, ensuring modeling of EES sta-tionary modes, and determining strengths of electromagnetic fields generated by power lines of different design. We demonstrate results of modes and electromagnetic fields modeling on routes of $220 \mathrm{kV}$ compact overhead power supply lines (COPL) with horizontal positioning of wires. For the purpose of comparison, similar calculations were performed for a typical overhead power line (TOPL). The modeling results allowed to formulate the following conclusions: when overall sections of COPL and TOPL are equal, the losses of active power in compact OPL are significantly lower; thus, when transmitted power is $375 \mathrm{MW}$, the losses in COPL are reduced by $45 \%$ compared to a typical $220 \mathrm{kV}$ OPL; at compact OPL receiver end a lower unsymmetry is observed; COPL ensure better electromagnetic safety conditions; electrical field strength at a height of 1.8 $\mathrm{m}$ for COPL axis is less than a similar index for TOPL by approximately 1.5 times; magnetic field in the same point is reduced to $60 \%$.
\end{abstract}

\section{Formulation of the problem}

Currently, a vast number of new overhead power lines designs is offered featuring an expanded capacity that allows to considerably raise power transport efficiency $[1-16]$. Compact OPL with expanded capacity deserve special attention, as they provide the following positive effects:

- to reduce twofold the land plots alienated for OPL construction;

- to reduce OPL impact on environment and population due to reduction in electromagnetic field's strength levels;

- to expand power lines transmission capacity by 1.2 ... 1.6 times;

- to reduce by $10 \ldots 20 \%$ specific expenses for $1 \mathrm{MW}$ of power transmitted;

- to reduce power losses and raise EES reliability.

To use such OPL, adequate methods and means are required to determine electrical energy sys-tems modes that include such lines. No less urgent is the task of electromagnetic fields (EMF) modeling created by these OPL.

The article provides results of computer modeling of compact power lines with horizontal po-sitioning of split-phase wires.

\section{Computer modeling methods}

The set of tasks formulated above on modes and compact OPL electromagnetic fields modeling, can be resolved based on EES methods of modeling in phase coordinates suggested by Irkutsk state transport university [17]. Fazonord software application [17] developed on their basis allows to calculate modes of EES and electromagnetic fields of non-traditional design OPL [16, $18-23]$. An efficient approach to modeling of multiwire elements with mutual inductive and capacitive couplings using lacelike equivalent networks, is implemented in the software application. The use of this method allows to model different types of multiwire lines with a large number of wires.

In this case, the OPL under consideration is viewed inseparably with a complex electrical energy system. Below, are the results of modes and electromagnetic fields modeling of compact $220 \mathrm{kV}$ overhead power supply line with wires positioning shown in figure 1, a

Typical $220 \mathrm{kV}$ overhead line modeling is provided for comparison (figure 1,b). COPL wires cross-section is assumed to be equal to $150 \mathrm{~mm}^{2}$, and TOPL -600 $\mathrm{mm}^{2}$. Thus, total cross-section of OPL in the both

\footnotetext{
* Corresponding author: bn 900@mail.ru
} 


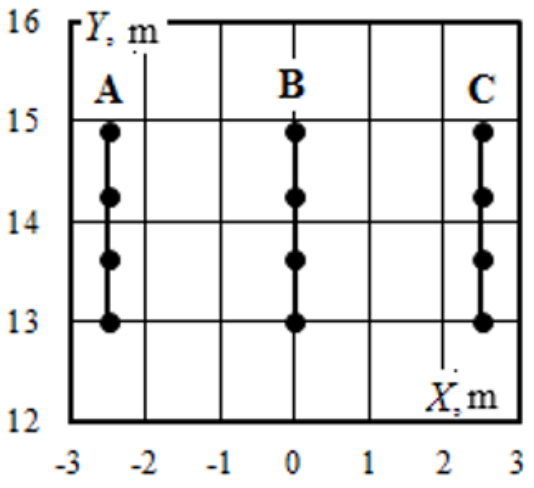

a)

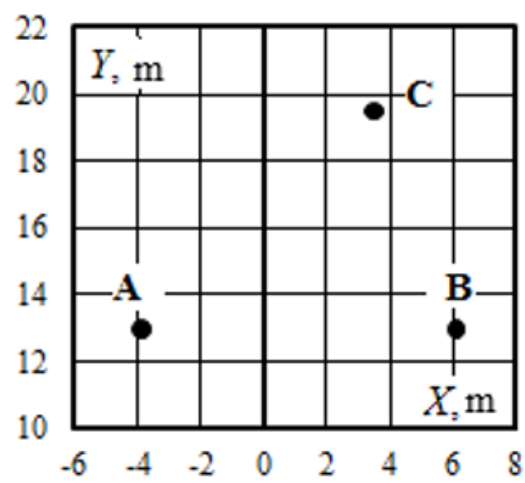

b)

Fig. 1. Wire coordinates: a - compact overhead power line; b - typical overhead power line.

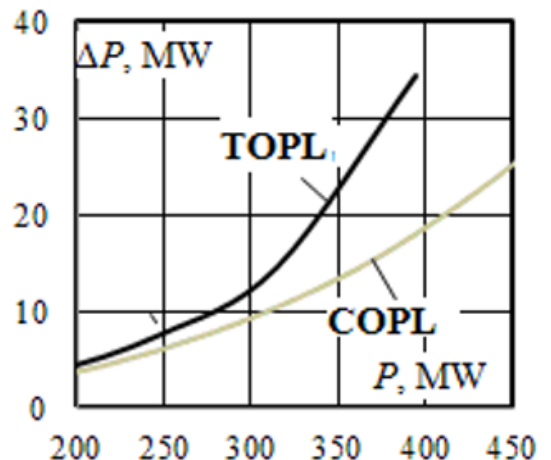

a)

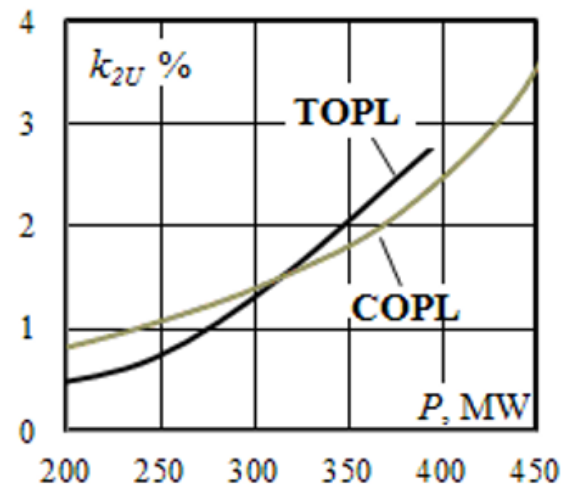

c)

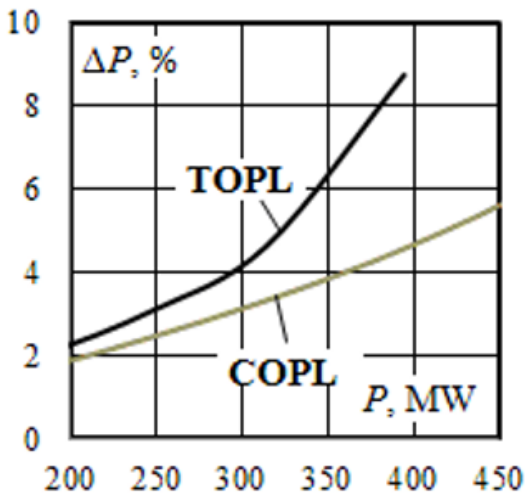

b)

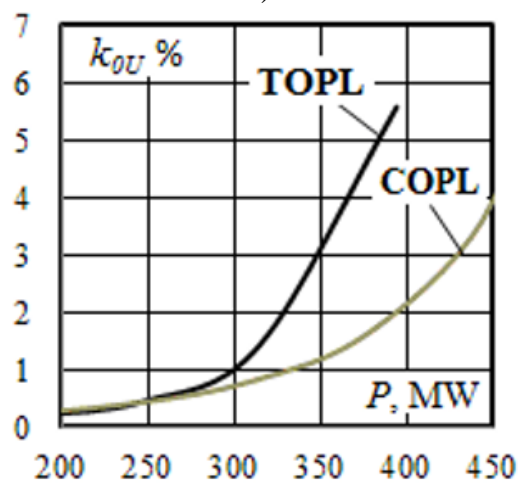

d)

Fig. 2. Dependence of mode parameters on power transferred: a - losses in MW; b - losses in percent; c - negative sequence unsymmetry coefficient; $d$ - zero sequence asymmetry coefficient.

options remains equal. Modeling was performed using Fazonord-APC software application.

\section{Computer modeling results}

Modes modeling results are provided in figure 2 as dependences of losses in OPL and unsymmetry coefficients by the negative and zero sequences on the power transmitted amount. In figure $3-5$ results of electrical and magnetic fields modeling are provided at the beginning of OPL at a height of $1.8 \mathrm{~m}$ from the ground surface. EMF calculations were carried out when load at OPL receiver end was equal $50+j 50 \mathrm{MW} \cdot \mathrm{A}$ and OPL length $50 \mathrm{~km}$. Figure 3 provides correlation of strengths amplitudes for COPL and TOPL. Figure 4 provides similar diagrams for active electromagnetic energy flux at a height of $1.8 \mathrm{~m}$. Figure 5 provides hodographs of strengths vectors in a point with coordinates $X=0 \mathrm{~m} ; Y=1.8 \mathrm{~m}$. Figure 6 provides spatial diagrams characterizing EMF strengths distribution in space surrounding TOPL wires.

The results obtained indicate the following:

1. Compact OPL allow to reduce twofold the area of a land plot which has to be occupied for OPL construction.

2. When overall section of COPL and TOPL is equal, the losses of active power in compact OPL are significantly lower; thus, when transmitted power is 375 


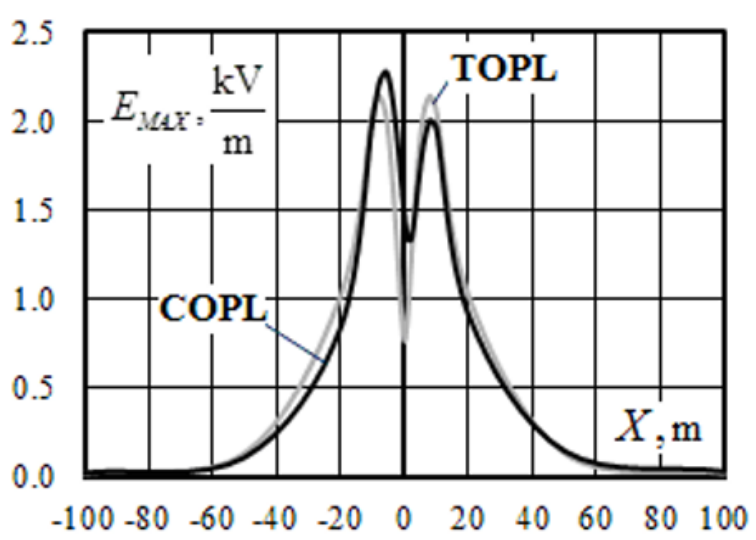

a)

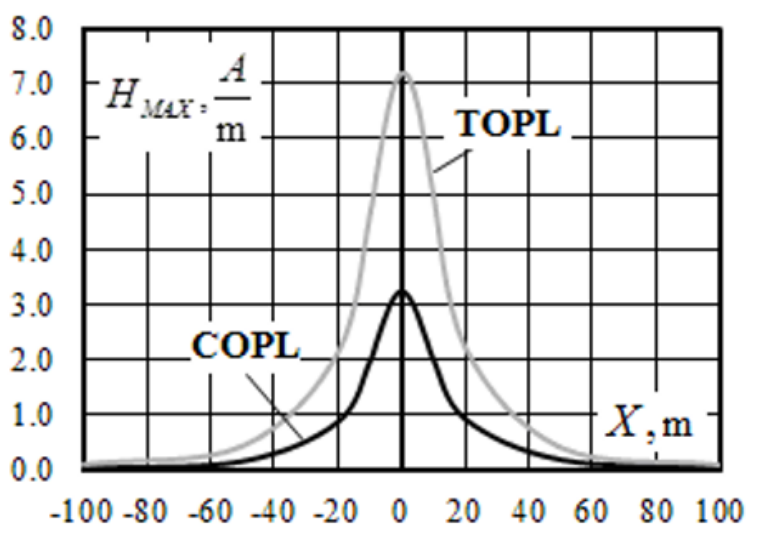

b)

Fig. 3. Strength distribution along the horizontal axis of a compact power line: a - electric field; $b$ - magnetic field.

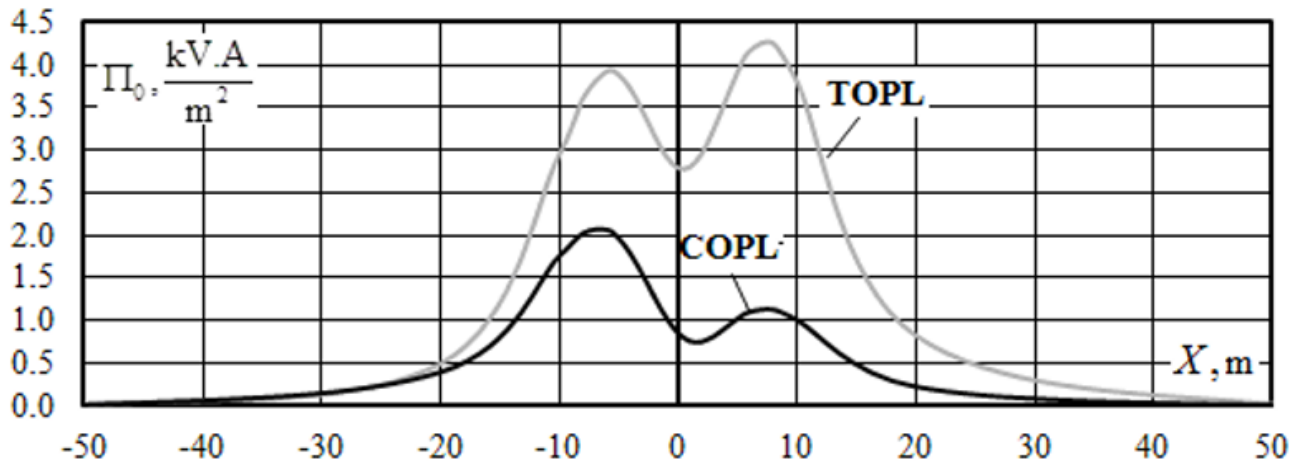

Fig. 4. Active electromagnetic energy flow at the height of $1.8 \mathrm{~m}$.

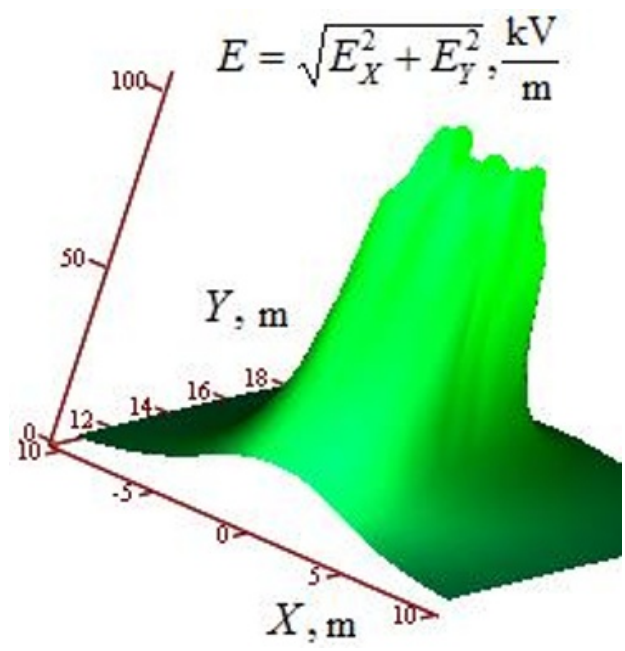

a)

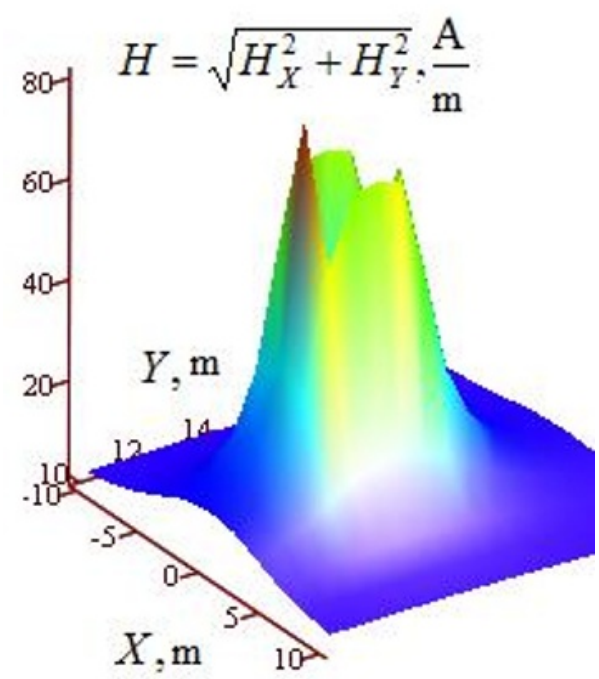

b)

Fig. 6. Electromagnetic field intensity surfaces: a - electric field; b - magnetic field.

MW, the losses in COPL are reduced by $45 \%$ compared with typical $220 \mathrm{kV}$ OPL.

3. At compact OPL receiving end lower unsymmetry is observed; COPL ensure better electromagnetic safety conditions. Electrical field strength at a height of $1.8 \mathrm{~m}$ for COPL axis is lower than a similar TOPL index approximately by 1.5 times; for magnetic field the reduction in strength in the same point reaches a double value.

4. Compact OPL has a significantly higher limit for power transmitted compared with a line of traditional design. 
4. Y.G. Skakaryan, L.V. Timashova, S.N. Kareva,

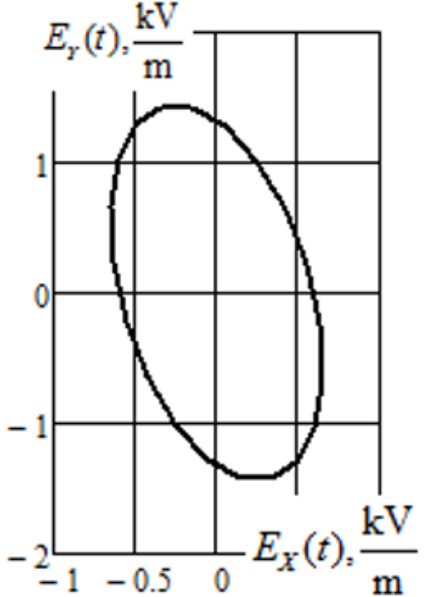

a)

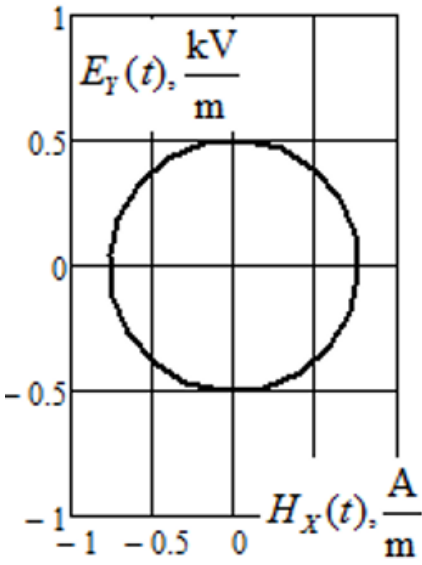

c)

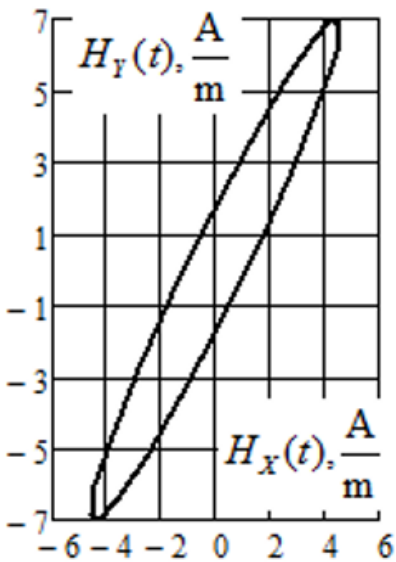

b)

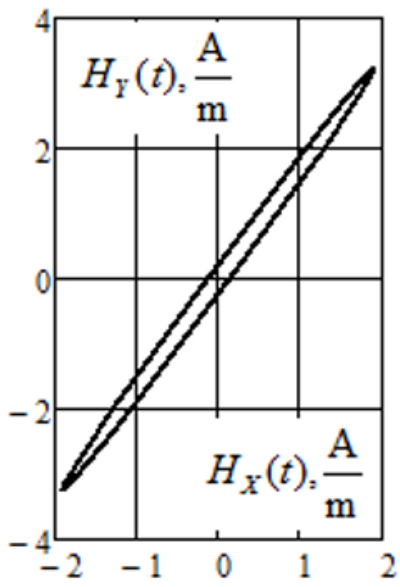

d)

Fig. 5. Dependence of electromagnetic field strength on time and hodograph of strength vectors in the point with coordinates $X$ $=0 \mathrm{~m} ; \mathrm{Y}=1.8 \mathrm{~m}: \mathrm{a}, \mathrm{c}$ - electric field; $\mathrm{b}, \mathrm{d}$ - magnetic field; $\mathrm{a}, \mathrm{b}$ - typical overhead power line; $\mathrm{c}, \mathrm{d}$ - compact overhead power line.

\section{Conclusion}

We present the method and results of modeling of electromagnetic fields generated by compact overhead power lines with expanded capacity. We demonstrate that using such lines allows to raise powers transmitted via OPL, to reduce electrical energy losses and improve energy quality at the OPL receiving end. Due to wires compact positioning, the area of land plots alienated for OPL construction is reduced approximately twofold.

\section{References}

1. G.N. Alexandrov, Modes of overhead power line operation, 139 (2006)

2. A.F. Dyakov, Electric grids of extra-high and ultrahigh voltage of power electric systems of Russia, Theoretic basis, 3, 368 (2012)

3. V.M. Stepanov, V.Y. Karnitsky, Compact power lines, News of the Tula state university. Technical Sciences, 3-5, 49-51 (2010)
V.M. Postolaty, Efficiency of transferring electric power in controlled compact overhead lines, Energy of a unified grid, 3(14), 4-15 (2014)

5. Y.G. Skakaryan, L.V. Timashova, S.N. Kareva, V.M. Postolaty, Technical aspects of creation and mode peculiarities of operation in 220-500 kV controlled compact overhead power lines, Energy of a unified grid, 4(4), 36-43 (2012)

6. G.K. Zarudsky, Y.S. Samaluk, Mode peculiarities of $220 \mathrm{kV}$ compact overhead power lines, Electricity, 5, 813 (2012)

7. V.V. Sotnikov, V.V. Kamaev, Comparative analysis of modern overhead power lines and perspectives of their development, Electrician, 9, 2-4 (2013)

8. E.N. Zuev, Overview of electric power transmission problems, Electro, 2, 2-5 (2005)

9. E.V. Bykova, V.M. Suslov, Y.G. Shakaryan, L.V. Timashova, Efficiency of controlled compact overhead lines, Problems of regional power industry, 3, 1-17 (2015)

10. G.I. Seliverstov, A.V. Komar, V.N. Petrenko V N, Structures and parameters of compact single circuit 
power lines with concentric arrangement of phases, Power Industry, 6, 41-45 (2012)

11. E.V. Bukova, Y.G. Shakaryan, L.V. Timashova, V.M. Postolaty, Main principles of creation and features of controlled self-compensating power lines, Electric and computation systems, 25, 216-229 (2017)

12. D.I. Chipizubov, A.M. Konstantinov, Mode limitations of $220 \mathrm{kV}$ multi-circuit compact overhead power lines, Scientific-technical-economic cooperation of Asian-Pacific Region countries in XX1 century, 1, 257-264 (2018)

13. E.V. Bukova, Y.G. Shakaryan, V.M. Suslov, Methodical approaches to select variants of new generation power lines. $220 \mathrm{kV}$ overhead power line case study, Problems of regional power industry, 2, 1-18 (2010)

14. V.N. Petrenko, G.I. Seliverstov, Physical model of compact transmission of increased natural capacity, Buletin of Gomel State Technical University, 3, 35-38 (2003)

15. E.Y. Sveshnikova, S.V. Makoldin, Technical and economical comparison of a $220 \mathrm{kV}$ compact fourcircuit power line and a $500 \mathrm{kV}$ single-circuit conventional power line, Modern Science Potential, 1(32), 4-7 (2018)

16. S.G. Murzin, Analysis of modern structures and systems of alternating current power lines by optimal throughput capacity and electric power minimal losses, Energy supply and saving in agricultural industry, 1, 206-213 (2008)

17. N.V. Buyakova, V.P. Zakaryukin, A.V. Kryukov, L.V. Thao, Model operation of the electromagnetic fields created by compact multisegment power line, Collection of scientific works of the Angarsk state technical university, 152-161 (2018)

18. V.P. Zakaryukin, A.V. Kryukov, Complex unbalanced modes of power systems, 273 (2005)

19. N.V. Buyakova, V.P. Zakaryukin, A.V. Kryukov, Electromagnetic safety in electric supply systems of railway: modelling and control, 382 (2018)

20. N.V. Buyakova, V.P. Zakaryukin, A.V. Kryukov, Modeling of electrical fields in railway engineering structures, Advances in Engineering Research, 158, 219225 (2018)

21. N.V. Buyakova, V.P. Zakaryukin, A.V. Kryukov, Imitative Modelling of Electromagnetic Safety Conditions in Smart Power Supply Systems, Advances in Intelligent Systems Research. Vth International workshop "Critical infrastructures: contingency management, intelligent, agent-based, cloud computing and cyber security", 158, 20-25 (2018)

22. N.V. Buyakova, V.P. Zakaryukin, A.V. Kryukov, T. Nguyen, Electromagnetic Safety Enhancing in Railway Electric Supply Systems, Web of Conferences 58, 1-6 (2018)

23. N.V. Buyakova, A.V. Kryukov, L.V. Thao, Modelling of compact power lines with vertical wire arrangement, Bulletin of Irkutsk State Technical University, 22(11), 159-169 (2018) 